\title{
IMPLEMENTASI METODE WATERFALL PADA SISTEM INFORMASI PEMBELIAN BAHAN BAKU PT. ANUGERAH CITRA SEJAHTERA
}

\section{Muhamad Tabrani ${ }^{1}$, Eni Pudjiarti ${ }^{2}$}

${ }^{1}$ Sistem Informasi, Universitas Bina Sarana Informatika Kampus Karawang

Jl. Banten No. 1 Karangpawitan Karawang, e-mail: muhammad.mtb@bsi.ac.id

${ }^{2}$ Teknik Informatika, Universitas Nusa Mandiri

Jl. Jatiwaringin No.2, Cipinang Melayu Makasar, Jakarta Timur, e-mail: eni.epr@nusamandiri.ac.id

\section{ARTICLE INFO}

Article history:

Received 30 September 2020

Received in revised form 2 Oktober 2020

Accepted 10 Oktober 2020

Available online 22 Oktober 2020

\begin{abstract}
PT. Anugerah Citra Sejahtera is a company engaged in construction development services and marketing in the property sector. Currently in the running system the process of purchasing raw materials still uses a manual recording process which is recorded in the raw material procurement stock book, when viewed from the business side, the process of purchasing raw materials has a very important role in a company process, where if the recording process of raw materials is not done properly or the process of recording lost data storage can cause problems for the company. In addition, by manually recording the data processing process will take a very long time and if necessary the data will not be fast and accurate. Designing Information Systems using the waterfall method, information systems that are made easier to control and well scheduled for the process, besides that this method is very suitable for making applications on a large scale considering the development model is the most reliable and widely used by developers. A raw material purchasing information system for PT. Anugerah Citra Sejahtera computerized which is intended so that the recording of purchases can run more effectively and efficiently and the data processing can be accurate and on time. The correctness of the data calculation is also guaranteed because it has been programmed properly and the incoming data has been validated and computers always verify the data.
\end{abstract}

Keywords: Waterfall method, Information System

\footnotetext{
Abstrak

PT. Anugerah Citra Sejahtera perusahaan yang bergerak dibidang jasa pengembangan kontruksi dan pemasaran di bidang properti. Saat ini di sistem berjalan proses pembelian bahan baku masih menggunakan proses pencatatan seacara manual yang dicatat dalam buku stok pengadaan bahan baku, jika dilihat dari sisi bisnis proses pembelian bahan baku memiliki peran yang sangat penting dalam sebuah proses perusahaan, dimana jika proses pencatatan bahan baku tidak dilakukan dengan baik atau proses penyimpanan data
} Received September 30, 2020; Revised Oktober 2, 2020; Accepted Oktober 22, 2020 
pencatatan hilang dapat menimbulkan masalah bagi perusahaan. Selain itu juga dengan pencatatan secara manual proses pengolahan data akan membutuhkan waktu yang sangat lama serta apabila diperlukan datanya tidak akan cepat dan akurat. Perancangan Sistem Informasi dengan menggunakan metode waterfall, sistem informasi yang dibuat lebih mudah untuk dilakukan pengontrolan serta terjadwal dengan baik prosesnya pengerjaanya, selain itu juga metode ini sangat cocok untuk pembuatan aplikasi dengan skala yang besar mengingat model pengembanganya paling handal dan banyak di gunakan para developer.Sebuah sistem informasi pembelian bahan baku PT. Anugerah Citra Sejahtera secara komputerisasi yang dimaksudkan agar kegiatan pencatatan pembelian dapat berjalan lebih efektif dan efisien dan pengolahan datanya dapat akurat dan tepat waktu. Perhitungan data juga terjamin kebenarannya karena sudah terprogram dengan baik dan data yang masuk telah divalidasi serta komputer-komputer selalu melakukan verifikasi terhadap data tersebut.

Kata Kunci: Metode waterfall, Sistem informasi

\section{PENDAHULUAN}

Di era globalisasi saat ini perkembangan tehnologi informasi berkembang sangat cepat sekali, dimana perusahaan saat ini mulai memanfaatkan tehnologi informasi sebagai suatu kebutuhan dalam menghadapi persaingan. Kondisi saat ini juga menuntut lembaga pemerintahan maupun swasta untuk dapat menyajikan data khususnya di bidang informasi dengan secara cepat dan tentunya seakurat mungkin. Teknologi informasi sekarang ini semakin modern, peningkatan teknologi informasi tersebut merupakan sebuah inovasi. Hasil dari perkembangan ilmu dan teknologi sangat berpengaruh terhadap aspek kehidupan Manusia [1]. Pengadaan bahan baku merupakan rencana penting dalam pembuatan keputusan strategis perusahaan, Perusahaan dapat menentukan kapan bahan baku harus disediakan, berapa jumlah bahan baku yang dipesan dan berapa jumlah bahan baku yang dibutuhkan oleh perusahaan dengan adanya pengadaan bahan baku [2]. PT Anugerah Citra Sejahtera merupan perusahan yang bergerak dibidang jasa pengembangan kontruksi serta pemasaran di bidang properti.

Dalam perusahaan jasa properti proses pembelian bahan bahan baku mempunyai peranan yang sangat penting dalam hal proses produksi, jika proses pembelian tidak dilakukan dengan baik khususnya proses pencatan dapat menimbulkan permasalahan bagi perusahaan. Saat ini permasalah yang dihadapi PT. Anugerah Citra Sejahtera adalah waktu permintaan dan pelaporan pembelian yang terlalu singkat, kesalahan dalam proses permintaan atau pemesanan bahan baku, kesalahan dalam laporan pembelian dan kurangnya informasi yang dihasilkan oleh sistem yang berjalan yang dapat membantu pihak manajemen dalam pengambilan keputusan. Hal ini terjadi karena dalam proses pembelian dan pengolahan data pada sistem berjalan yang belum memadai, karena proses yang dilakukan secara manual.

Untuk membantu menyeselesikan permasalah tersebut, diperlukakanya sistem informasi yang berbasis komputer sehingga nantinya dapat menghasilkan data yang akurat dan tepat dalam pengambilan keputusan, menentukan kebijakan dan rencana pembelian. Dengan demikian perusahaan dapat menentukan kapan pembelian harus dilakukan, berapa banyak yang harus dibeli dan menghasilkan laporan yang akurat dan tepat.

\section{TINJAUAN PUSTAKA}

2.1. Konsep Dasar Sistem

Konsep dasar sistem merupakan sekelompok elemen yang berbasis komputer hasil karya manusia berfungsi mengelola data, menyimpan, menghimpun kerangka kerja, serta mengkoordinasikan sumber daya manusia dan komputer untuk mengubah sistem masukan menjadi sistem keluaran untuk mencapai tujuan dan sasaran yang telah ditetapkan sebelumnya. Pengertian sistem menurut Romney dan Steinbart [3] Sistem adalah rangkaian dari dua atau lebih komponen-komponen yang saling berhubungan, yang berinteraksi untuk mencapai suatu tujuan. Sebagian besar sistem terdiridari subsistem yang lebih kecil yang mendukung sistem yang lebih besar.

Sistem informasi pembelian adalah sebuah sistem yang bertujuan mengidentifikasi kebutuhan dari informasi pembelian yang digunakan untuk pengambilan keputusan. Dengan adanya sistem informasi pembelian perusahaan dapat memiliki data supplier yang nantinya di gunakan dalam memesan barang , serta jatuh tempo pembayaran sehingga tidak telat dalam membayar kewajiban membayar hutang, kemudian laporan - laporan mengenai pembelian, supplier, barang -barang yang dibutuhkan, menjaga persediaan agar selalu ada, kapan harus melakukan reorder point, akan up to date dan akurat[4].

\subsection{Bahasa Pemograman}

JURNAL ILMIAH ELEKTRONIKA DAN KOMPUTER, Vol.14, No.1, Juli 2021 
p-ISSN: 1907-0012 e-ISSN : 2714-5417

Menurut Munir dalam ebook [5] menyimpulkan bahwa "Program adalah algoritma yang ditulis dalam bahasa komputer". Pemrograman adalah proses mengimplementasikan urutan langkah untuk menyelesaikan suatu masalah dengan menggunakan bahasa pemrograman. Penulisan program biasanya menggunakan program editor yang telah disediakan oleh bahasa pemrograman yang dipilih.

Program adalah kumpulan intruksi yang digunakan untuk me- ngatur komputer agar melakukan suatu tindakan tertentu. Tanpa adanya program komputer hanyalah perangkat keras (hardware) yang tidak bisa melakukan apa-apa[3].

Dalam pembuatan sistem informasi pembelian bahan baku PT. Anugerah Citra Sejahtera beberapa bahasa pemograman yang diperlukan:

\subsubsection{Basis Data}

Basis data (database) adalah kumpulan informasi yang disimpan di dalam komputer secara sistematik sehingga dapat diperiksa menggunakan suatu program komputer untuk memperoleh informasi dari basis data tersebut. Perangkat lunak yang digunakan untuk mengelola dan memanggil kueri (query) basis data disebut sistem manajemen basis data atau database management system (DBMS). Sistem basis data

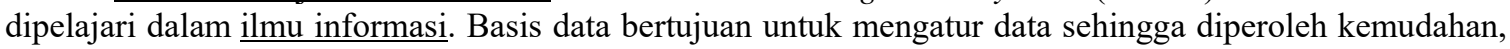
ketepatan dan kecepatan dalam pengembalian kembali. Untuk mencapai tujuannya, syarat sebuah basis data yang baik adalah sebagai berikut: tidak adanya redudansi, inkonsistensi data, kesulitan pengaksesan data dan multiple user[6]. Basis Data adalah sekumpulan data yang saling berhubungan secera logis beserta deskripsinya, yang digunakan secara bersama-sama dan dirancang untuk memenuhi kebutuhan informasi disuatu tempat[7].

MySQL database server adalah RDBMS (Rasional Database Management System) yang dapat menangani data yang bervolume besar.Meskipun begitu, tidak menuntut resource yang besar. MySQL adalah database yang paling popular diantara database-database yang lain. MySQL adalah program database yang mampu mengirim dan menerima data dengan sangat cepat dan multi user menurtut wahana komputer dalam jurnal[2].

2.2.2. Bahasa Pemrograman Microsoft Visual Basic.net

Visual Basic adalah salah satu bahasa pemrograman berbasis desktop yang di keluarkan (diproduksi) oleh perusahaan perangkat lunak komputer terbesar yaitu Microsoft". Visual Basic merupakan salah satu bahasa pemrograman paling laris dan paling sukses di dunia. Visual Basic yang didukung penuh oleh produsennya (Microsoft) selalu dikembangkan dan disesuaikan dengan kebutuhan zaman seperti penyesuaian model pemrograman modern yang berbasis OOP (Object Oriented Programming)[8].

\subsection{Tool Sistem Pendukung}

\subsubsection{Entity Relationship Diagram (ERD)}

Entity Relationship Diagram (ERD) adalah[6]: suatu model jaringan yang menggunakan susunan data yang disimpan dalam sistem secara abstrak. Jadi, jelaslah bahwa ERD ini berbeda dengan DFD yang merupakan suatu model jaringan fungsi yang akan dilaksanakan oleh sistem, sedangkan ERD merupakan model jaringan data yang menekankan pada struktur-struktur dan relationship data. Elemen-elemen dalam Diagram Hubungan Entitas meliputi :

a. Entity Pada E-R Diagram, Entity dapat digambarkan dengan sebuah bentuk persegi panjang. Entity adalah sesuatu apa saja yang ada di dalam sistem, nyata maupun abstrak dimana data tersimpan atau dimana terdapat data.

b. Relationship Pada E-R Diagram, Relationship dapat digambarkan dengan sebuah bentuk belah ketupat. Relationship adalah hubungan alamiah yang terjadi antara entitas. Pada umumnya penghubung (Relationship) diberi nama dengan kata kerja dasar, sehingga memudahkan untuk melakukan pembacaan relasinya (bisa dengan kalimat aktif atau pasif).

\subsubsection{Logical Record Structure (LRS)}

Logical Record Structured (LRS) [6]:adalah representasi dari struktur record-record pada tabel-tabel yang terbentuk dari hasil relasi antar himpunan entitas". Menentukan kardinalitas, jumlah tabel, dan Foreign Key (FK). Berikut adalah cara membentuk skema database atau LRS (Logical Record Strutured) berdasarkan Entity Relationship Diagram:

a. Jika relasinya satu-ke-satu, maka foreign key diletakan pada salah satu dari dua entitas yang ada tau menyatukan kedua entitas tersebut.

b. Jika relasinya satu-ke-banyak, maka foreign key diletakan pada entitas Many.

c. Jika relasinya banyak-ke-banyak, maka dibua "file konektor" yang berisi dua foreign key yang berasal dari kedua entitas. 


\subsubsection{Unified Modelling Language (UML)}

UML (Unifed Modelling Language) adalah[9]: salah satu standar bahasa yang digunakan di dunia industry untuk mendefinisikan requirement, membuat analisis dan desain, serta menggambarkan arsitektur dalam pemograman berorientasi objek. UML merupakan bahasa visual untuk pemodelan dan komunikasi mengenai sebuah sistem dengan menggunakan diagram dan teks-teks pendukung. UML mempunyai beberapa atau sejumlah elemen grafis yang bisa dikombinasikan menjadi diagram. Diagram tersebut akan menggambarkan atau mendokumentasikan beberapa aspek dari sebuah sistem.

a. Use Case Diagram

Use case [9] merupakan pemodelan untuk kelakuan (behavior) sistem informasi yang akan dibuat. Use case mendeskripsikan sebuah interaksi antara satu atau lebih aktor dengan sistem informasi yang akan dibuat.

b. Diagram Aktivitas (Activity Diagram)

Activity diagram [9] menggambarkan workflow (aliran kerja) atau aktivitas dari sebuah sistem atau proses bisnis atau menu yang ada pada perangkat lunak". Yang perlu diperhatikan disini adalah bahwa diagram aktivitas menggambarkan aktivitas sistem bukan apa yang dilakukan aktor, jadi aktivitas yang dapat dilakukan oleh sistem.

\section{METODOLOGI PENELITIAN}

3.1 Metode Pengembangan Perangkat Lunak

Untuk membangun sebuah sistem yang berbasis komputer dapat digunakan beberapa metode sebagai acuan. Dalam penelitian ini menggunakan metode waterfall yang terbagi menjadi lima tahapan, yaitu [9]:

a. Analisis Kebutuhan Perangkat Lunak

Pada tahap ini, penulis melakukan analisa terhadap kebutuhan pengguna yang menjelaskan fasilitas apa saja yang diperoleh dan dapat digunakan oleh user. Berdasarkan permasalahan yang diuraikan pada latar belakang maka penulis menemukan kebutuhan apa saja yang digunakan, yaitu dalam kebutuhan user adalah admin memiliki hak akses untuk dapat mengelola keseluruhan data master baik dalam proses input data baru, edit data, hapus data, cetak data dan difokuskan pada kegiatan transaksi dan informasi. Dalam kebutuhan sistem user harus login terlebih daluhu untuk dapat masuk sistem dan setelah selesai user dapat melakukan logout.

b. Desain

Pada tahap ini penulis terlebih dahulu membuat entity relationship diagram (ERD), logical record structure (LRS), kemudian diimplementasikan menjadi program pada tahap selanjutnya.

c. Pengkodean

Hasil dari tahap ini adalah program komputer sesuai dengan desain yang telah dibuat pada tahap desain.

d. Pengujian

Pada tahap pengujian, penulis melakukan uji coba menggunakan metode blackbox testing yang bertujuan untuk menemukan kesalahan dalam fungsi-fungsi yang salah atau hilang.

e. Pendukung (support) atau pemeliharaan (maintenance)

Tidak menutup kemungkinan ketika sebuah software dipindah tangankan atau dikirim ke user mengalami perubahan karena ada kesalahan yang tidak terdetiksi saat pengujian dilakukan, untuk pemeliharaan suatu software sangat diperlukan, karena tidak menutup kemungkinan mengalami perubahan dan pengembangan ketika perusahaan ada penggantian atau penambahan dalam sistem operasinya, baik penambahan menu dan lain-lain.

3.2 Teknik Pengumpulan Data

Tehnik pengumpulan data yang penulis gunakan dalam pengumpulan data dalam pembuatan Sistem Informasi Pembelian bahan baku adalah sebagai berikut[10]:

a. Observasi

Metode yang dilakukan penulis dengan mengadakan pengamatan langsung pada PT. Anugerah Citra Sejahtera, pada bagian pembelian untuk mengetahui prosedur dan sistem berjalan pada saat itu, sebagai acuan membuat sistem informasi pembelian bahan baku.

b. Wawancara

Metode yang dilakukan oleh penulis dengan mempelajai serta menanyakan informasi-informasi yang berhubungan dengan masalah dalam proses pembelian bahan baku pada PT. Anugerah Citra Sejahtera kepada staff bagian pembelian dan pimpinan perusahaan

c. Studi Pustaka

JURNAL ILMIAH ELEKTRONIKA DAN KOMPUTER, Vol.14, No.1, Juli 2021 


\section{p-ISSN: 1907-0012 e-ISSN : 2714-5417}

Suatu bentuk metode yang dilakukan dengan kajian literatur yang berkaitan dengan judul tugas akhir ini serta kajian dari jurnal-jurnal terkait dari web yang bertujuan untuk mendukung data yang telah didapat dalam referensi buku-buku yang berkaitan dengan objek riset.

\section{HASIL DAN PEMBAHASAN}

4.1 Tahap Perancangan Sistem

4.1.1. Analisa Kebutuhan

Setelah penulis mempelajari sistem berjalan pada PT. Anugerah Citra Sejahtera dan mengetahui permasalahan-permasalahan yang ada pada sistem berjalan saat ini, maka penulis mengajukan suatu usulan dan menjelaskan lebih lanjut mengenai sistem pembelian bahan baku ke dalam sistem yang terkomputerisasi. Dengan menggunakan sistem usulan ini bertujuan dalam mengumpulkan data dan pengolahan datanya dapat dilakukan dengan cepat, tepat, dan akurat dalam menghasilkan data dan informasi yang dapat dipertanggungjawabkan.

1. Kebutuhan Pengguna

Dalam aplikasi pembelian bahan baku terdapat empat pengguna yang dapat saling berinteraksi dalam lingkungan sistem, yaitu: bagian staff pembelian, inventory staff, finance \& accounting dan Production Division Head. Keempat pengguna tersebut memiliki karakteristik interaksi dengan sistem yang berbeda-beda dan memiliki kebutuhan informasi yang berbeda-beda, seperti berikut:

a. Kebutuhan Staff Pembelian

1) Mengolah permintaan bahan baku

2) Menerbitkan Purchase Order

3) Mengolah penerimaan bahan baku

4) Membuat rekap tagihan

5) Membuat laporan pembelian

b. Kebutuhan Inventory Staff

1) Mengolah stok bahan baku

2) Menerbitkan Purchase Requisition

3) Dapat Melihat Tanda Terima

c. Kebutuhan Finance \& Accountin

1) Dapat Melihat Receiving Slip

2) Dapat Melihat Tanda Terima

3) Dapat melihat rekap tagihan

4) Dapat melihat laporan pembelian

d. Kebutuhan Production Division Head

1) Dapat melihat rekap tagihan

2) Dapat melihat laporan pembelian

3) Setting user

4) Back up data

2. Kebutuhan Sistem

a. Pengguna harus melakukan login terlebih dahulu untuk dapat mengakses aplikasi ini dengan memasukkan username dan password agar privasi masing-masing pengguna tetap terjaga keamanannya.

b. Pengguna harus melakukan logout setelah selesai menggunakan aplikasi. 
4.1.2. Usecase Diagram

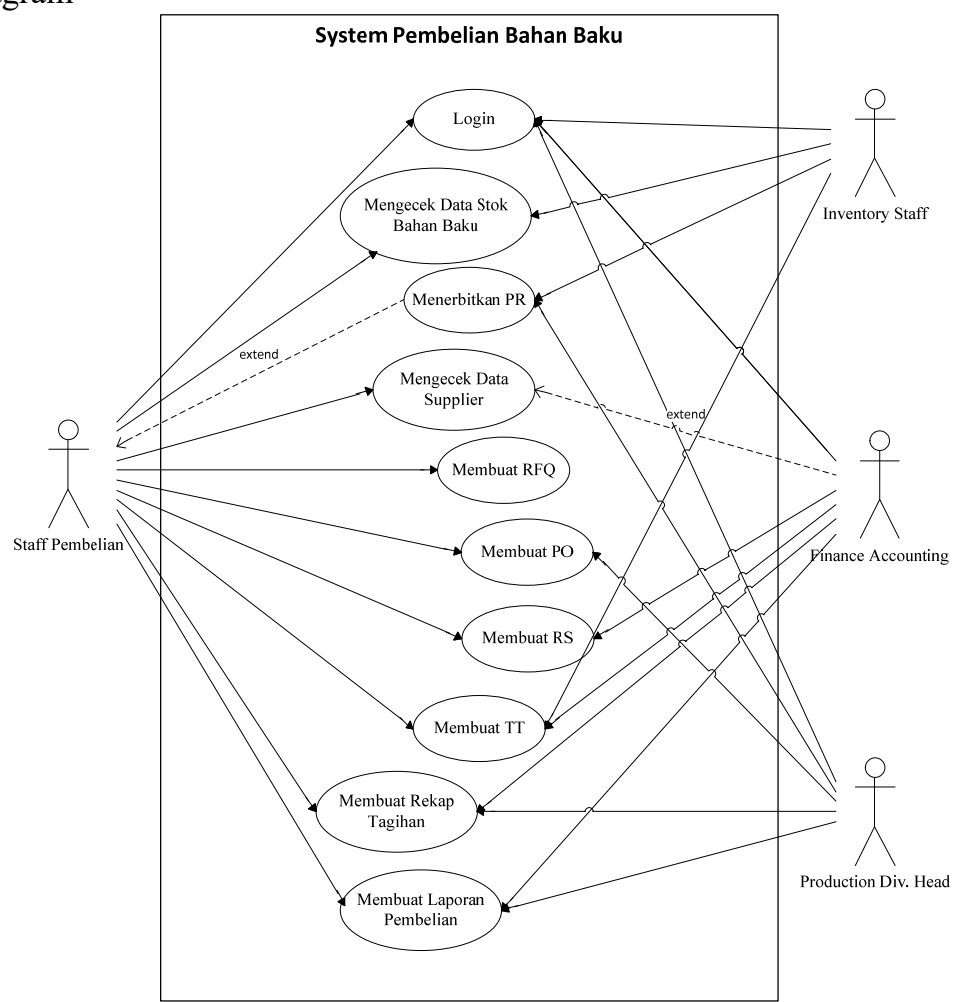

Gambar 1. Usecase Diagram

4.1.3. Activity Diagram

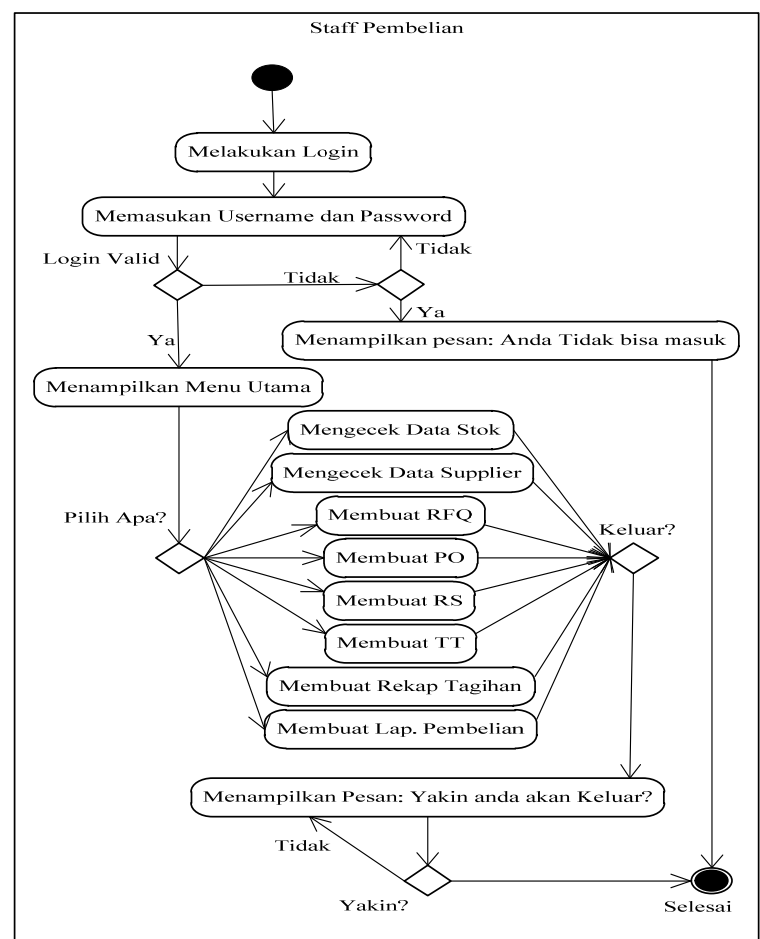

Gambar 1. Activity diagram Bagian Pembelian

JURNAL ILMIAH ELEKTRONIKA DAN KOMPUTER, Vol.14, No.1, Juli 2021 
7

p-ISSN: 1907-0012 e-ISSN : 2714-5417

4.1.4. Rancangan Prototype

1. Rancangan Prototype Login

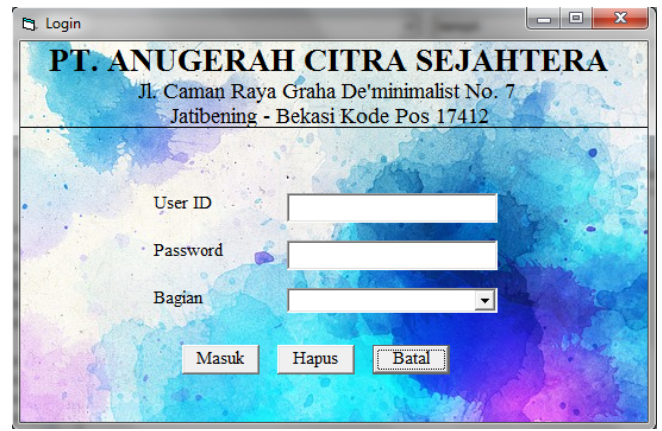

Gambar III Tampilan Menu Login

2. Rancangan prototype Transaksi

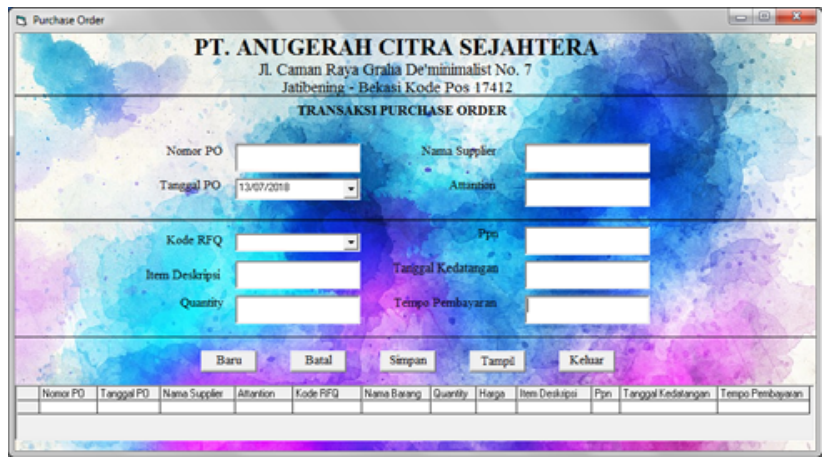

Gambar IV Tampilan Transaksi Purchase Order

4.2 Perancangan Perangkat Lunak

4.2.1. Entity Relationship Diagram (ERD)

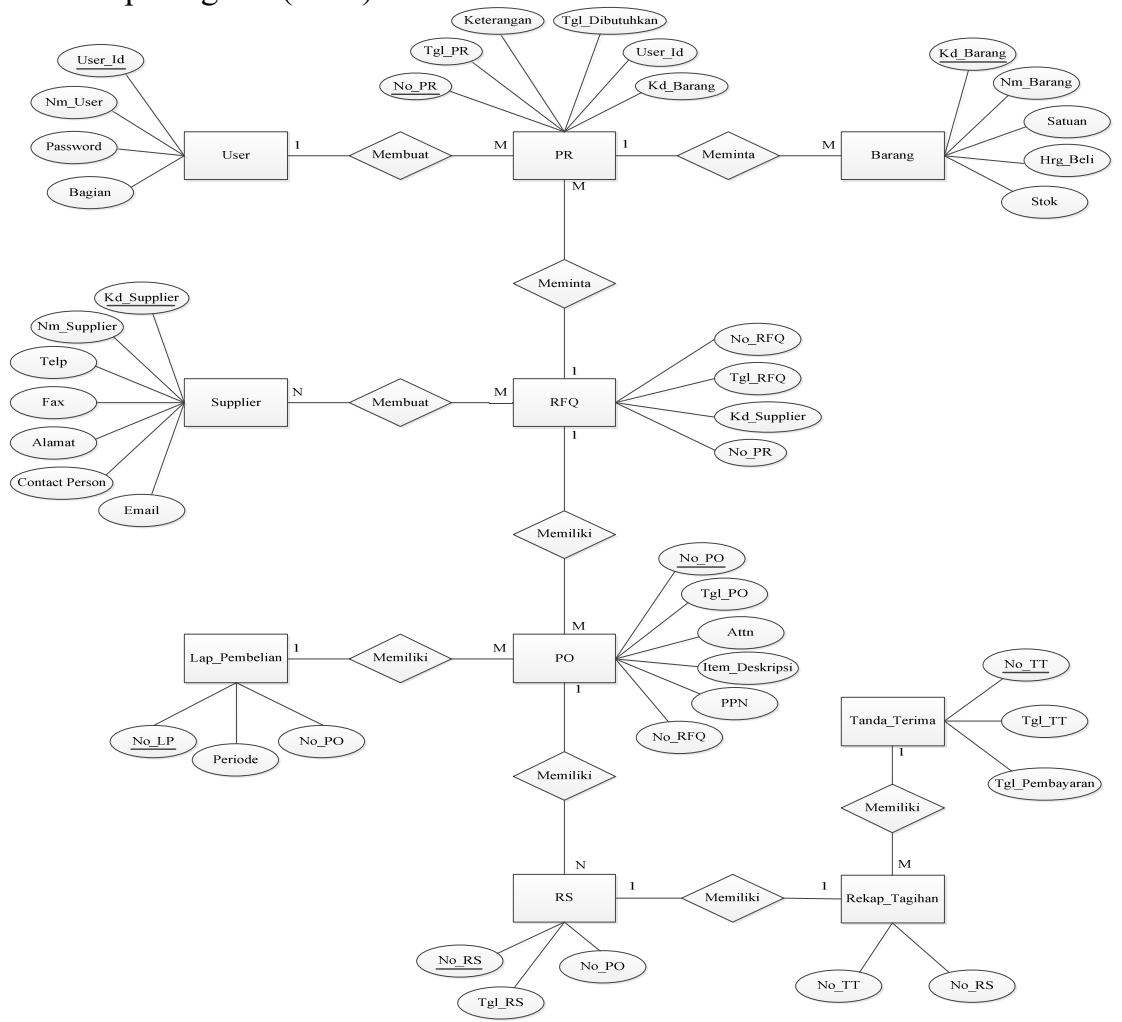

Gambar V Entity Relationship Diagram (ERD) 
4.2.2. Logical Record Structure (LRS)

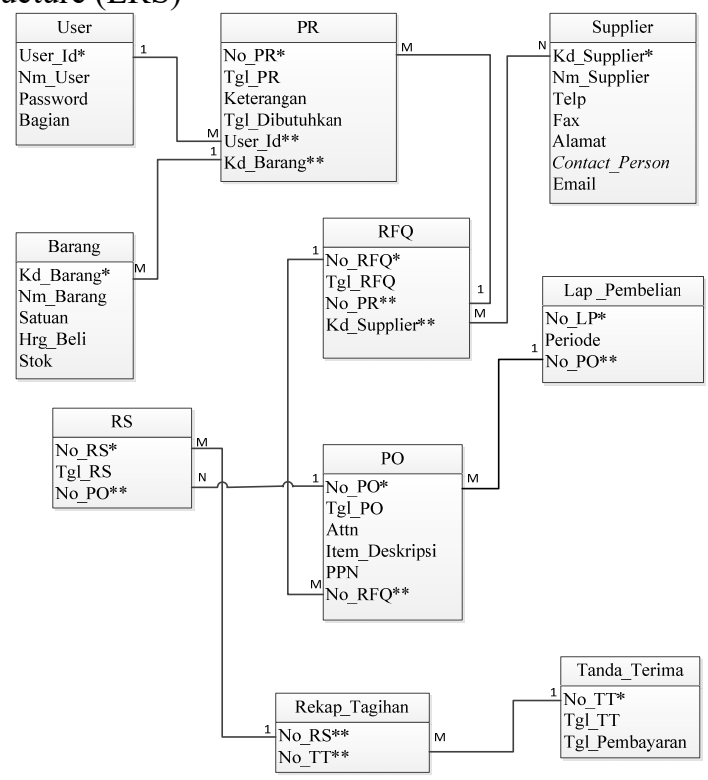

Gambar VI Logical Record Structure (LRS)

4.2.3. Spesifikasi Hardware dan Software

Komponen perangkat keras adalah unsur-unsur yang terdiri dari perangkat keras komputer yang digunakan untuk membantu proses kerja manusia (brainware) dan bersifat fisik, terdiri dari (CPU), monitor, keybord, harddisk, disk, drive, mouse, dan printer.

$\begin{array}{ll}\text { Processor } & : \text { Windows } 7 \\ \text { RAM } & : 1 \mathrm{~Gb} \\ \text { Monitor } & : \text { LCD } \\ \text { CD RW } & : 700 \mathrm{MB} \\ \text { Hard Disk } & : 250 \text { Giga Byte } \\ \text { Keyboard } & : 108 \text { keys } \\ \text { Mouse } & : \text { PS2 } \\ \text { Printer } & : \text { Epson }\end{array}$

Komponen perangkat lunak adalah serangkaian unsur-unsur yang terdiri dari beberapa perangkat lunak program komputer yang digunakan untuk membantu proses kerja manusia (brainware) dan sifat non fisik, terdiri dari sistem software dan application software.
Sistem Operasi : : Microsoft Windows 7
Package Program : Visual Basic NET
Database : :MySQL

\section{KESIMPULAN DAN SARAN}

5.1. Kesimpulan

Setelah penulis mengamati dan mempelajari sistem pembelian bahan baku yang ada pada PT. Anugerah Citra Sejahtera maka penulis dapat mengambil kesimpulan sebagai berikut:

1. Perancangan sistem pencatatan secara terkomputerisasi yang dimaksudkan agar kegiatan pencatatan pembelian dapat berjalan lebih efektif dan pengolahan datanya dapat akurat dan tepat waktu. Perhitungan data juga terjamin kebenarannya karena sudah terprogram dengan baik dan data yang masuk telah divalidasi serta komputer-komputer selalu melakukan verifikasi terhadap data tersebut.

2. Dengan adanya sistem yang terkomputerisasi akan memudahkan pemakai dalam membuat laporan yang akurat dan tepat waktu.

3. Dengan sistem yang baik diharapkan akan meningkatkan kinerja perusahaan dan juga produktivitas perusahaan dan karyawan. 
5.2. Saran

Setelah mengambil kesimpulan mengenai analisa sistem pembelian bahan baku pada PT. Anugerah Citra Sejahtera, penulis akan mencoba memberikan saran-saran yang berhubungan dengan kegiatan pembelian dalam perusahaan.:

1. Mengingat pentingnya data yang tersimpan dalam file, maka penulis perlu dibuatkan file duplikat (back up) untuk setiap file yang digunakan agar jika terjadi kerusakan, perusahaan tidak kehilangan data tersebut dan kegiatan perusahaan tidak terhenti karena akan mengakibatkan kerugian bagi perusahaan.

2. Melakukan pemeliharaan terhadap peralatan komputer baik dari segi perangkat keras (hardware) maupun perangkat lunak (software) sehingga sistem terkomputerisasi akan berjalan dengan baik.

3. Ada pengembangan sistem informasi berupa pemasangan jaringan yang bisa online antar user.

4. Perlu melakukan training untuk para user supaya mudah untuk mengoperasikan program yang baru.

\section{DAFTAR PUSTAKA}

[1] R. Farmasi and M. Taniah, "RANCANG BANGUN SISTEM INFORMASI BOOKING MEETING ROOM ONLINE PADA PT . KIMIA FARMA,” vol. 9, no. 2, pp. 89-91, 2020.

[2] I. Diantra Ava, S. D. Nuris, and T. Wulandari, "PENERAPAN METODE MATERIAL REQUIREMENT PLANNING ( MRP ) UNTUK SISTEM INFORMASI PENGADAAN BAHAN BAKU PADA CV . AINTZANE MANDIRI,” vol. 13, no. 1, pp. 103-115, 2020.

[3] H. Priyandaru, Walim, and M. Tabrani, "MANAJEMAN INFORMASI PERSEDIAAN BARANG BERBASIS WEB PADA CV H. SYARIDIN KARAWANG,” J. AKSARA PUBLIC, vol. 4, no. 3, pp. 1-9, 2020.

[4] H. HENDARTI, “SISTEM INFORMASI PEMBELIAN," https://sis.binus.ac.id/, 2021. [Online]. Available: https://sis.binus.ac.id/2014/05/08/sistem-informasi-pembelian/.

[5] Z. Saputra, "Belajar Cepat Membuat Aplikasi Menggunakan Visual Basic . Net + DB MYSQL," 2016, pp. 1-61.

[6] A.-B. Bin Ladjamudin, Analisis dan desain Sistem Informasi. Yogyakarta: Graha Ilmu, 2013.

[7] D. Putri and W. Gata, "Rancang Bangun Website Desa Demangharjo," vol. 13, no. 2, pp. 49-61, 2020.

[8] W. Komputer, Microsoft Visual Basic.net dan MySQL. Andi Offset, 2012.

[9] M. S. Rosa A S, Rekayasa Perangkat Lunak. Bandung: Informatika, 2016.

[10] I. Kurniawan, Abdussomad, F. Akbar, D. Saepudin, and M. Tabrani, "Improving The Effectiveness of Classification Using The Data Level Approach and Feature Selection Techniques in Online Shoppers Purchasing Intention Prediction Improving The Effectiveness of Classification Using The Data Level Approach and Feature Selecti," 2020. 